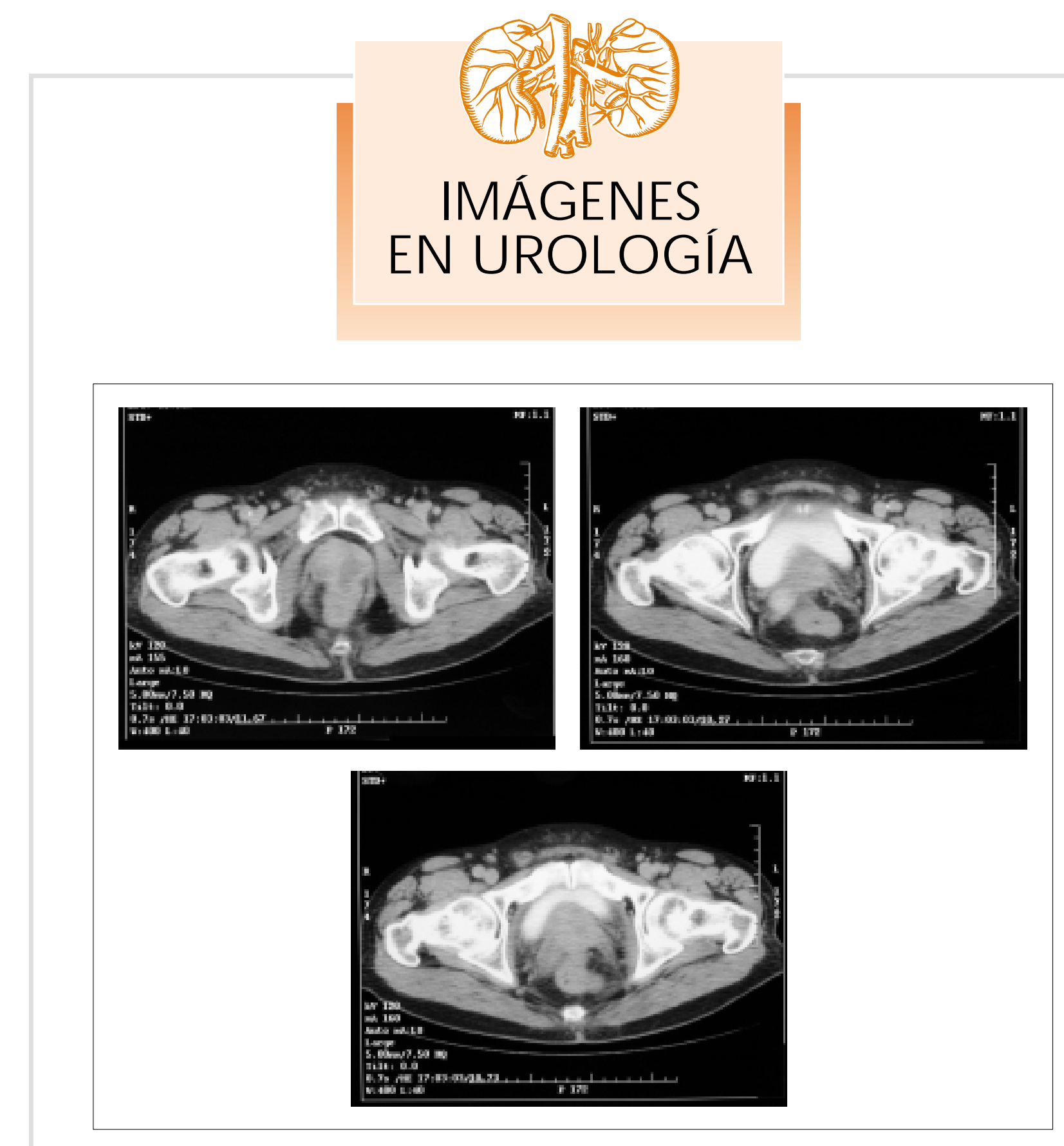

\title{
RABDOMIOSARCOMA DE PRÓSTATA
}

Paciente varón de 67 años de edad con antecedentes de diabetes mellitus e hipertensión que consulta en urgencias por tenesmo rectal y dolor perineal de unos quince dias de evolución acompañados de un sindrome constitucional. Al tacto rectal se evidencia una masa en cara anterior del recto irregular y pétrea. En la ecografía trasrectal la próstata es heterogénea y se encuentra rodeada por una banda hipoecoica sin poder descartar origen prostático o rectal. La tomografia computerizada abdominopélvica(TC) describe una imagen hipodensa intraprostática a nivel del lóbulo izquierdo, con limites imprecisos y pérdida de los planos grasos compatible con proceso tumoral. La biopsia trasrectal confirmó el diagnóstico de rabdomiosarcoma tipo pleomórfico a nivel de la encrucijada vésico-prostática. Se decide quimioterapia neoadyuvante a cirugia de exanteración pélvica.

M. Musquera Felip, J.Ma. Rodríguez de Ledesma, A. Cetina Herrando, J. Salvador Bayarri, H. Villavicencio Mavrich. Unidad de Urgencias. Servicio de Urología. Fundació Puigvert. Hospital de Santa Creu i Sant Pau. Barcelona. 